\title{
Delayed Occurrence of CSF Oculorrhea after Mild Blunt Traumatic Head Injury
}

\author{
Sang Bin Choi, Sang Pyung Lee, Jin Wook Baek, Tae Joon Park \\ Department of Neurosurgery, Cheju Halla General Hospital, Jeju, Korea
}

Received: June 3, 2019

Accepted: July 8, 2019

Corresponding Author:

Tae Joon Park, M.D.

Department of Neurosurgery,

Cheju Halla General Hospital, 65,

Doryeong-ro, Jeju 63127, Korea

Tel: +82-64-740-5000

Fax: +82-64-740-5655

E-mail:rmbmcic@gmail.com
Cerebrospinal fluid (CSF) oculorrhea is very rare after traumatic head injury. CSF fistula can cause hazardous complications including infection of central nervous system(CNS). A 40-year-old male visited with epiphora occurring every morning. He underwent traumatic head injury about a year and a half ago. Intrathecal Gadolinium-Enhanced Magnetic Resonance (MR) Cisternography was performed to diagnose his CSF oculorrhea. The delayed CSF oculorrhea was successfully treatment with continuous lumbar drainage. This case report discusses the diagnosis and treatment of the very rare case of the delayed CSF oculorrhea after mild blunt traumatic head injury.

Keywords: CSF oculorrhea; Delayed; CSF fistula; Traumatic head injury

\section{INTRODUCTION}

Cerebrospinal fluid (CSF) fistula is an uncommon but well-documented phenomenon which occur after head trauma, typically manifesting as otorrhea or rhinorrhea ${ }^{2,5)}$. CSF rhinorrhea and otorrhea are relatively common complications of head injuries to compare with CSF oculorrhea ${ }^{5)}$. Although it is rare, CSF could enter the orbit following a anterior cranial fossa injury and CSF can exit via the eye, mimicking tear formation ${ }^{10}$.

The paucity of reported CSF oculorrhea cases, especially compared with the frequency of other types of CSF fistulas developing after traumatic head injury, suggests that cranio-orbital fistulas are rare and may be underdiagnosed complications ${ }^{8)}$.

CSF fistula can cause hazardous complications including infection of central nervous system (CNS), intracranial hypotension, seizures, etc ${ }^{1,8)}$. Therefore, early detection and treatment is required. But CSF oculorrhea is very rare ${ }^{1,3,5,6,9)}$ and it is difficult to diagnose early, because it need to differentiate CSF oculorrhea from excessive lacrimation caused by orbital soft tissue trauma or epiphora caused by lacrimal outflow obstruction ${ }^{2,8)}$.

Therefore, any patient who presents with excessive posttraumatic drainage through the orbit should be suspected to have CSF oculorrhea ${ }^{9}$.

In this report, the diagnosis and management of one rare case of delayed CSF oculorrhea after mild blunt cranio-orbital trauma is discussed.

\section{CASE REPORT}

On October 5, 2018, a 40-years-old male who underwent traumatic head injury about a year and a half ago, visited our outpatient department. The patient complained of epiphora occurring every morning. In glucose stick test at local medical center, blood sugar level has been checked $110 \mathrm{mg} / \mathrm{dL}$, and tear's sugar had been checked $68 \mathrm{mg} / \mathrm{dL}$. Under suspicion of CSF leakage, the patient was admitted for a thorough examination. 
In his past history, there was a car accident against truck on the highway on February 25, 2017. The traumatic epidural hemato$\mathrm{ma}(\mathrm{EDH})$ and subdural hematoma(SDH) with a linear skull fractures (lateral wall of left sided orbit, temporal, and sphenoid bone) was revealed in his craniofacial computerized tomography(CT) scanning (Fig. 1) but the amount of these hematoma was only scanty and conservative management was done.

Although the patient suffered from left sided facial paralysis and otorrhagia, due to left sided temporal bone fracture. These symptoms were improved gradually and in the end, there was no CSF leak at the time of discharge.

Based on the patient's past history and the glucose level of the eye drop, the CSF oculorrhea was suspected strongly. To confirm CSF leak, Intrathecal Gadolinium-Enhanced Magnetic Resonance (MR) Cisternography (Fig. 2) was performed and CSF collection was identified in inferior part of both orbits and nasopharynx with unidentified fistula site in MRI findings. In spite of conservative treatment with absolute bed rest, CSF oculorrhea was persisted, and we performed continuous lumbar drainage and it was maintained for two weeks.

The lumbar drainage catheter removed in two weeks and there was no more CSF leakage during the hospitalization and there were no complications such as cerebral meningitis either. After he discharged, the patient visited our outpatient department 2 weeks and 6 weeks later and there was no CSF leakage any more.

\section{DISCUSSION}

CSF leakage typically occurs at four anatomical locations, which is the frontal sinus, the cribriform plate and ethmoid roof, the sphenoid sinus, and the petrous bone ${ }^{8,9)}$, and it occurs due to the defect of anatomical barriers (the skin or mucosa of the air sinuses, the periosteum, the skull bones, the dura mater, and the arachnoid membrane $)^{8,9)}$. When CSF leakage occurred after head trauma, two thirds of the cases occurred within the first 48hours, and the most cases, the leakage detected within 3 months ${ }^{8)}$.

CSF otorrhea (CSF leaks through the temporal bone or mastoid fracture associated with dural tears into the middle ear), and CSF rhinorrhea (CSF leaks through fracture of cribriform plate associated with dural tears into the paranasal sinuses and nasal cavity) $)^{2)}$ occur commonly, because of a relatively high-pressure gradient between the intracranial space and the external ear canal or paranasal sinuses $^{2)}$. But CSF oculorrhea is rare, because of the relative low pressure gradient between the intracranial subarachnoid space and the intraorbital space ${ }^{2)}$.

In the history of oculorrhea, a case of profuse CSF drainage through the orbit following avulsion of the eye was documented first by Walsh and $\mathrm{Hoyt}^{9}{ }^{9}$. And tear like-CSF leakage have been described by Joshi KK, Crockard $\mathrm{HA}^{7}$. The CSF leakage through the orbit was termed 'oculorrhea' by Salame K et al. ${ }^{9}$.

In the reported 16 case of the oculorrhea ${ }^{2,4,8,9,10)}$ (Table 1). It oc-
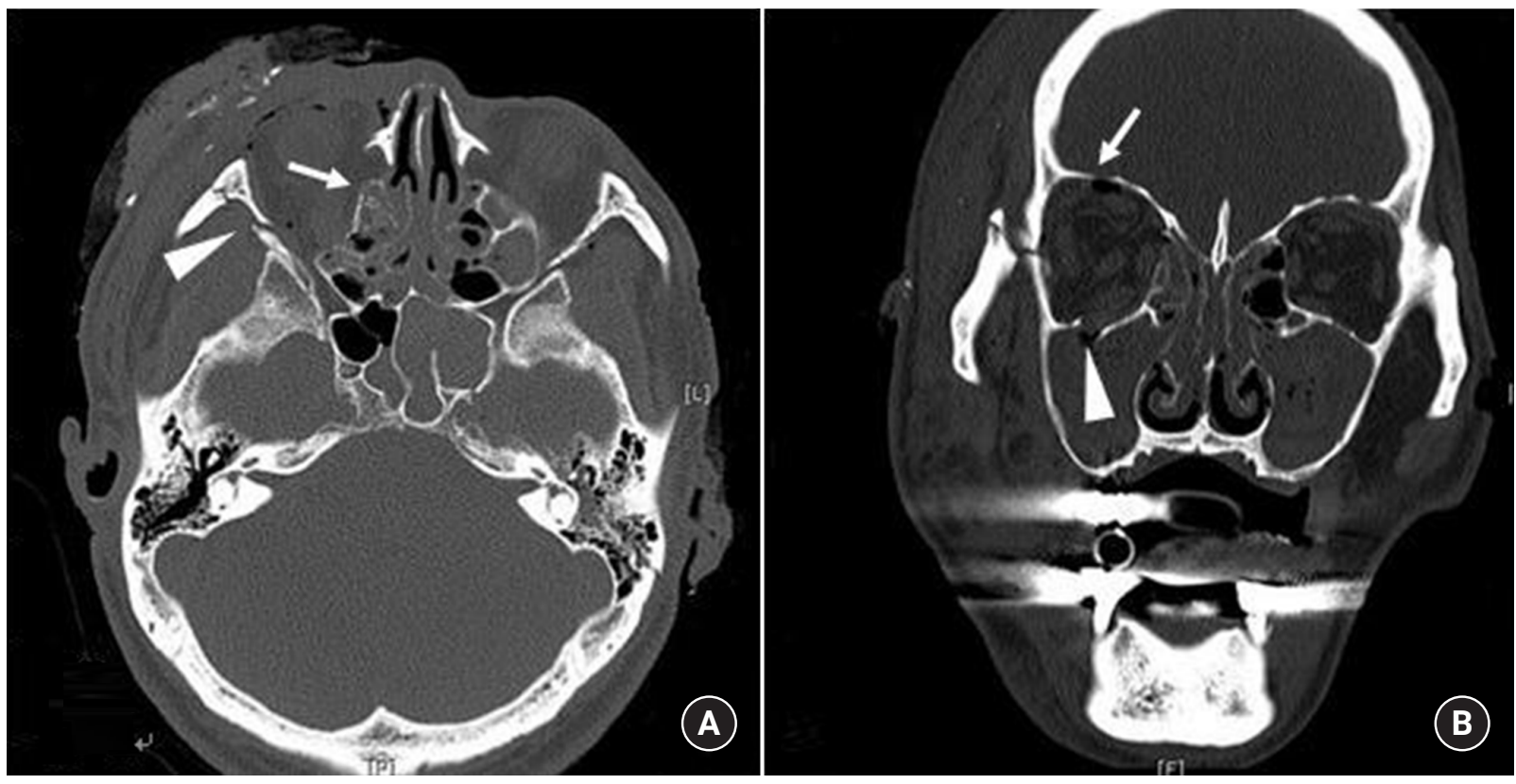

Fig. 1. Craniofacial computed tomography. A. Axial view shows fracture involving right ethmoid bone(arrow) and lateral orbital wall fracture(arrowhead). B. Coronal view show comminuted fracture involving right frontal bone extent into orbital roof(arrow) and maxillary sinus(arrowhead). 


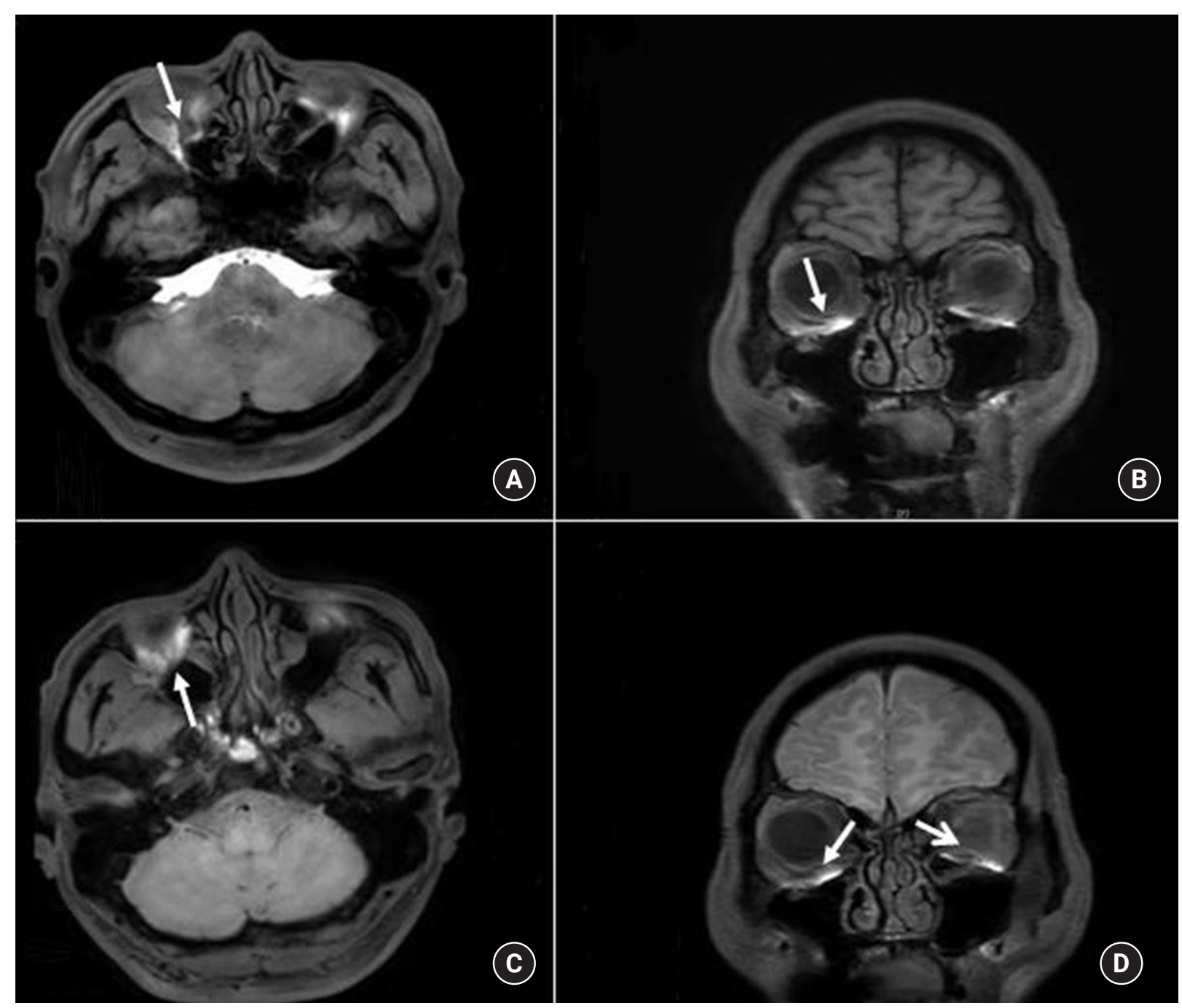

Fig. 2. Intrathecal Gadolinium-Enhanced MR Cisternography. Axial A and Coronal B T1W1 immediately following the intrathecal demonstrate early partial enhancement (arrow). Axial C and Coronal D T1W1 following a 24h delay shows retention of contrast media in inferior part of both orbits and nasopharynx (arrow).

curred in the relative young ages by severe traumatic head injury within a week after traumatic head injury.

In our case, the patient was a 40 aged-man and he underwent mild blunt head trauma compare with other reported cases. In addition, it was detected in delayed period after trauma.

The delayed CSF oculorrhea can be explained by the persistent fistula between the cranium and orbit ${ }^{10)}$, but to establish the diagnosis of cranio-orbital fistula can be challenging because of the difficulty in differentiating oculorrhea from excessive lacrimation caused by orbital soft tissue trauma or epiphora caused by lacrimal outflow obstruction ${ }^{2}$.

Delayed CSF oculorrhea should be concerned for all patients with excess tearing after anterior skull fractures ${ }^{8)}$. Because it is difficult to know exactly when it happened. If the CSF oculorrhea detection is missed, the number of complications could be happen and the prognosis of patients should be poor ${ }^{1,8)}$. Therefore we should be suspect CSF oculorrhea in patients with eye drops who has the past history of skull base fracture especially frontal or orbital roof even it is only mild blunt injury ${ }^{8}$, and if the CSF oculorrhea is suspected, the diagnosis should be done immediately thorough examination and active management is required ${ }^{9)}$.

In the diagnosis of CSF oculorrhea, the analysis of the fluid for glucose concentration may be helpful ${ }^{4,8,9)}$ and Immunoassay for beta 2-transferrin is more specific and requires only a small amount of fluid ${ }^{8,9}$. CT cisternography with iopamidol followed by thin-sectioned coronal-view CT scanning through the bone window is the best method for localization of the fistula ${ }^{8,9}$. As in our patient, Intrathecal Gadolinium-Enhanced MR Cisternography can perform in the evaluation of CSF leakage ${ }^{1,3,5}$.

In most case, the initial management of CSF leak is conservative 
Table 1. CSF Oculorrhea case series list, clinical description

\begin{tabular}{|c|c|c|c|c|c|c|}
\hline Author & Year & Age & Sex & Mechanism of injury & Ocular sign on admission & Onset \\
\hline Bard & 1963 & $36 \mathrm{Y}$ & $\mathrm{M}$ & stabbing wound & Laceration & immediate \\
\hline Barker-Griffith & 2007 & $14 \mathrm{Y}$ & $\mathrm{M}$ & potatogun injury & Multiple lacerations and ecchymosis of lids & immediate \\
\hline Bongartz & 1981 & $2 \mathrm{Y}$ & $\mathrm{M}$ & falling injury & Swelling of right eyelid & immediate \\
\hline Civelek & 2006 & $7 \mathrm{Y}$ & $\mathrm{M}$ & stabbing wound & Proptosis; diplopia, orbital cellulitis; periorbital abscess & immediate \\
\hline Dryden & 1986 & $4 \mathrm{Y}$ & $\mathrm{M}$ & Motor vehicle & Right inferior oblique overreaction; meningeal signs & Immediate \\
\hline Garza-Mercado & 1982 & $20 \mathrm{Y}$ & $\mathrm{M}$ & assault & Edema and ecchymosis of eyelids, limited extraocular movements & Immediate \\
\hline Joshi & 1978 & $8 \mathrm{M}$ & $\mathrm{F}$ & Motor vehicle & Unconscious mentality mydriasis, fixed pupil, laceration & 5days later \\
\hline Joshi & 1978 & $5 \mathrm{Y}$ & & undisclosed & $\mathrm{N} / \mathrm{A}$ & Immediate \\
\hline Kjer & 1954 & $3 Y$ & $\mathrm{M}$ & stabbing wound & Unconscious mentality, Clonic spasm, upper lid edema, fixed pupil & Immediate \\
\hline Rao & 1999 & $78 \mathrm{Y}$ & $\mathrm{M}$ & stabbing wound & Meningeal signs, & Immediate \\
\hline Rha & 2012 & $56 \mathrm{Y}$ & $\mathrm{M}$ & Motor vehicle & Unconscious mentality papilledema, proptosis, mydriasis & Immediate \\
\hline Salame & 2000 & $20 \mathrm{Y}$ & $\mathrm{F}$ & Trauma: sports & Periorbital swelling and ecchymosis, laceration, mydriasis & Immediate \\
\hline Pease & 2012 & $22 \mathrm{Y}$ & $\mathrm{M}$ & Motor vehicle & Laceration, diminished ocular movements & Immediate \\
\hline Alexandra & 2014 & $34 \mathrm{Y}$ & $\mathrm{M}$ & Motor vehicle & periorbital swelling, limited extraocular movement, decreased sensation of V2 & 3days later \\
\hline Jain & 2016 & $52 \mathrm{Y}$ & $\mathrm{F}$ & $\begin{array}{l}\text { Post-surgery; } \\
\text { frontotemporal } \\
\text { craniotomy }\end{array}$ & third nerve palsy & immediate \\
\hline Sheth & 2018 & $16 \mathrm{Y}$ & $\mathrm{M}$ & Motor vehicle & extensive laceration, proptosis & 3days later \\
\hline
\end{tabular}

treatment ${ }^{8,9)}$. However, the rate of complications can increase in cases of delayed CSF oculorrhea, so active treatment is needed. It is important to preventing CSF leak through cranio-ocular fistula and to reduce at risk for infection within the central nervous system ${ }^{2,8,9)}$. We suggest that CSF diversion is proper method for the management of a traumatic cranio-orbital fistula ${ }^{6}$. CSF diversion can be performed continuous lumbar drainage for up to 10 days ${ }^{10)}$. In spite of continuous lumbar drainage, if the CSF continues to leak, a surgical approach can be taken to primarily repair the dural defect ${ }^{8,10)}$.

\section{CONCLUSION}

CSF leakage requires early diagnosis and early treatment, because it can cause serious complications ${ }^{4}$. CSF oculorrhea is very rare $^{1,3,5,6,9)}$. But, CSF leakage like tears can be occur in patients which is middle-aged man with trauma history even mild blunt head injury especially in the morning. We should be alert in early diagnosis of CSF leakage and immediate and adequate treatment is needed $^{4}$.

\section{NOTES}

\section{Conflict of interest}

No potential conflict of interest relevant to this article was reported.

\section{REFERENCES}

1. Antonelli V, Cremonini AM, Campobassi A, Pascarella R, Zofrea G, Servadei F. Traumatic encephalocele related to orbital roof fractures: report of six cases and literature review. Surg Neurol 2002;57:117-125.

2. Apkarian AO, Hervey-Jumper SL, Trobe JD. Cerebrospinal fluid leak presenting as oculorrhea after blunt orbitocranial trauma. J Neuroophthalmol 2014;34:271-273.

3. Chandra N, Ojha BK, Chandwani V, Srivastava C, Singh SK, Chandra A. A rare case of posttraumatic eyelid swelling: cerebrospinal fluid blepharocele. J Neurosurg Pediatr 2013;11:242-244.

4. Dryden RM, Wulc AE. Pseudoepiphora from cerebrospinal fluid leak: case report. Br J Ophthalmol 1986;70:570-574.

5. Govindaraju V, Bharathi R. Post-traumatic blepharocele in an adult. Sultan Qaboos Univ Med J 2013;13:E479-481.

6. Jain S, Patel RM, Hage Z, Lim J, Lee S, Amin-Hanjani S, et al. Cerebrospinal Fluid Leak Presenting as Epiphora. Ophthalmic Plast Reconstr Surg 2016;32:e26-28.

7. Joshi KK, Crockard HA. Traumatic cerebrospinal fluid fistula simulating tears. Case report. J Neurosurg 1978;49:121-123.

8. Pease M, Marquez Y, Tuchman A, Markarian A, Zada G. Diagnosis and surgical management of traumatic cerebrospinal fluid oculorrhea: case report and systematic review of the literature. J Neurol Surg Rep 2013;74:57-66.

9. Salame K, Segev Y, Fliss DM, Ouaknine GE. Diagnosis and management of posttraumatic oculorrhea. Neurosurg Focus 2000;9:e3. 
10. Sheth AA, Ngo V, Lam M. Traumatic cerebrospinal fluid oculorrhea managed with an external ventricular drain. J Surg Case Rep 2018;2018:rjy215. 